\title{
SMART INITIATIVE ON REGIONAL DEVELOPMENT THROUGH SMALL AND MEDIUM ENTERPRISE (SME) SECTOR UPLIFT!
}

\author{
*Syeda Asiya Zenab Kazmi \\ * Marja Naaranoja \\ University of Vaasa
}

\begin{abstract}
This article examines an effort by European Union in the form of BTP2, a specialized training resource offered to support the European small and medium sector entrepreneurs during the business transfer process, from one owner to another, in the current volatile European business environment. The article describes the varieties in entrepreneurial knowledge based behavioral approaches that are existent among the three European countries (i.e., Finland, Poland and Portugal) which were selected as the project pilots. The study findings revealed the European entrepreneurs' behavioral case potentials, weaknesses and the possible future efforts to support the local SME's survival plans through specialized focus on Business transfer process.
\end{abstract}

Keywords: Small And Medium Enterprises; Business Transfer Process; Entrepreneurial Behavioural Approaches; Case Potentials; Survival Plans

\section{INTRODUCTION}

'Inertia', as defined by a human genius, Newton, is a tendency of a non-stationary object to remain in motion or a motionless object to remain stationary till been acted upon by an opposite and comparatively greater level of force. Motte. A (1846). Such reality provides the basis for the concept of social inertia, 'We' the humans are social animals and do prefer to remain comfortable by completely submitting ourselves to our living habits. Consequently, such surrender to social inertia makes us the very part of the pressure it exerts on our overall social setup; social group or society. The only recommendable action to conquer the social inertia is to resist it by exerting greater level of force in the opposite direction to guarantee the betterment and progression of the society. The significance and influence of European Commission within the European environment is a key to successfully craft the multi-community development plans for the progression of the region, as a whole, in any field of life which requires attention. The European region is home to 27 member states with a forecast overall population of 503,679,730 as of 1st January 2012.(Bomberg, Elizabeth, Peterson, John, and Richard Corbett 2012).

The role of European Commission through its SMEs friendly initiatives marks the level of its efforts made for the enhancement of regional productive growth, by combating the negatives of unemployment and 
revitalising the competitiveness through its remarkable `Europe 2020 strategy`. For making the above true, European Commission has been witnessed as consciously following its Small Business Act (2008). The Small Business Act (SBA) depicts extensive amount of insight on European SME sector's performance level through the implementation of various success indicators, in line with the European Commission's overall SBA Action Plan. In accordance with the European Commission's report on the European SME Sector's Annual performance on 15th October, 2012, the facts are as below;

\section{Table 1: Reflection of the performance review on European SME's Sectors for 2012 - Source: Eurostat/ National Statistics Offices of Member States/Cambridge Econometrics/Ecorys)}

\begin{tabular}{|l|llll} 
Category of Enterprise & Micro level & Small & Medium & $\begin{array}{l}\text { Total Number of } \\
\text { SMEs in Europe. }\end{array}$ \\
\hline Number wise share. & $19,143,521$ & $1,357,533$ & 226,573 & $20,727,627$ \\
\hline People Employed & 38395819 & 26771287 & 22310205 & 87477311 \\
\hline Gross Value added (Euros in Million) & 1307360,7 & 1143935,7 & 1136243,5 & 53587540
\end{tabular}

In view of above, the aim of the study is to evaluate the efforts of European Commission through one of its multi -community development plans, named Business Transfer Programme 2 (BTP2) to up-lift the SME sector in the region, through the human resource development and training (i.e., the human resources include the prospective entrepreneurs- through the new business buyers to the business successors, mentors, as well as the other stakeholders - public sector policy makers, lawyers, financial experts, social activists etc.). The present research study aims at throwing light on the steps and processes taken to put the BTP2 plan in motion. The paper is organized in the following sequence; first, we introduce various concepts acting behind the need of the overall research activity along with briefly touching the key actors; i.e European Commission and the BTP2 plan implementers. In the Second phase, we review the current literature to define the concepts of entrepreneurs, small and medium enterprise and then we coalesce theories of business transfer process after breaking each component to frame our understanding of the concept of business transfer process in total. This framework then guides exploratory research into business transfer programme piloted in three European countries. The qualitative case studies, methodology and data analysis are then presented. We highlight issues that impact the understanding of business transfer process, proposing new angles to be included in similar future efforts by the regulators or the researcher for more comprehensive and cutting edge investigation. In the end the findings of the study are presented and discussed, followed by a conclusion describing the implications for researchers and practitioners, and additionally the limitations of the study just before closing the suggestive future avenues for further research.

\section{LITERATURE REVIEW}

The early definitions of 'Entrepreneur' by the Irish-French economist Richard Cantillon (1755/1931), followed by Jean-Baptiste Say (1803) or later by the renowned Harvard business professor Schumpeter (1934), the term was used to refer the individuals as the change leaders, breaking the economic status quo of the existing products and services, to initiate the process of economic activity by introducing new products and services. According to the OECD-Eurostat Entrepreneurship Indicators Programme, the entrepreneurs are defined as the business owners, who are involved in generating value, through either the creation or the 
expansion of an economic activity, by introducing and exploiting new products (Lazear, E.P. 2005)business processes or the markets', Ahmad and Seymour (2008).

There are three broad criterions to define the concept of SMEs:

- $\quad$ Micro-entities are the companies with the staff strength up to 10 employees;

- Small firms are the ones having 50 workers, whilst

- $\quad$ Medium-sized enterprises are identified as the ones having the employee strength up to 250.

However, in general, SMEs are also defined as firms with either the revenue limit up to $€ 10-50$ million or the balance sheet totalling up to $€ 10-43$ million. In addition, according to the European Commission, in their July 2011 statement ` there would be an open consultation on the definition of SMEs in 2012. The research investigations on the area of business transfers started getting attention since the late 1980's and till the mid2000s, the topic achieved significant level of interest especially by the family business researchers, with reference to the issues related to business succession process, (Langsberg, 1988, Husain, J. 2013, and Le Breton-Miller et al., 2004). The business exit event is significant for the business owners since at least for once in their lifetime each one of them has to undergo the business exit process which is either during life or, more realistically, at their death. (Cardon et al. 2005; Husain, J. 2009). A European Commission's 2002 report highlighted the business transfer process from the non-family perspective, highlighting the significance of small-firm transfers to national economies opening up the avenues of numerous firms following the suite. The above, caught extensive interest of the business transfer researchers. Van Teeffelen (2010) defined the process of business transfer as a process of ownership conversion of any firm or a business unit from one individual to another person or a legal entity with the continuous commercial existence of the enterprise with more than 50 present of assets or shares are transferred. In the business transfer buyers and the sellers are the two key instruments to initiate the process (Venter et al., 2003). However, most of the business owners have either very superficial knowledge or completely no knowledge or experience of the process of selling, buying and acquiring capital or legal knowhow for the business transaction. Hence, a majority of business buyers and sellers are assisted by a large number of advisors (i.e., experts on different knowledge areas), and among those, accountants are the most prominent actors (Allison et al., 2007) in the business transfer transection. However, evidence - based methods, low cost group programmes and follow - ups are needed to evaluate the skill level of the advisors and the success of the resultant business transection activity (Van Teeffelen, L. 2012). According to a research conducted in Cyprus, by Hadjimanolis and Dickson (2000), the process of business transfer process revealed a positive connection with the concept of business innovation as being the source of generating new ideas and opportunities. The resultant outcome is alternatively, termed as 'development response' by the business successors, that can either be a family member, external manager or the purchaser.

The results of various studies conducted in different countries on the process of business transfer strongly suggest that only few firms survive while going through the intergenerational transfer. According to the research studies conducted by Kets de Vries (1993) on the business survival in USA, it was revealed that only $30 \%$ of the firms survive into the second generation of family ownership, while only $15 \%$ into the third. In addition, the inability of an owner-manager to 'let go' of the business is a serious hindrance for an effective business succession process (Sharma et al., 2001). The data gathered through the above referred studies revealed that the core reasons for such pattern was mainly associated with the personal factors such as 
educational and independent career desires pursued by the successors (i.e., especially the offspring) of the entrepreneurs (Bachkaniwala et al., 2001). The researchers in their studies on business transfer try to forecast the prospects of the very transaction and the post-transfer performance of that business venture (e.g. Meijaard et al., 2005). According to one of the statements by the Netherlands Ministry of Economic Affairs (2003) on the capacity of business survival after going through the transfer process, it was assessed that the chances of a successful transfer as directly related to the similarities between the skills and style of the business transferor (i.e., old business owner) and the business transferees (i.e., the new entrepreneurs). A research by Martin et al. (2001) on the small business service, revealed the following critical factors leading to the firms at risk of transfer failure;

- The business is designed in a manner that it meets the owner's personal 'lifestyle' goals, instead of focusing on the overall strategic corporate objectives,

- Low level of business performance,

- The business is too much dependent on the owner's personal knowledge base, views and aspirations (of markets, customers, systems, etc.) - such knowledge potential cannot be easily transferred to a successor,

- Non availability of a suitable or willing successor manager drawn from the ranks of employees or the owner's family,

- The absence of any (medium-term) plans for transfer.

Human capital encompasses the formal education, age, gender, experience, skills and knowledge of entrepreneurs (Becker, 1975), and is developed through education, training and personal experience. One study by Berent et al. (2009) confirmed that the firms whose successors got more work exposure from outside the company gained decreased level of post-transfer profitability. However, proper planning and successor's skill level enhancement showed increased post-transfer profits in family-to-family transfers. The above and many similar studies, the proved a strong base to understand the need of BTP2 initiative by the European commission and the researchers involved.

\section{RESEARCH SETTING}

The team of training experts, consultants and able researchers from seven European countries (i.e.; Austria, Finland, Netherland, Poland, Portugal, Italy and Sweden) joined their hands to form an international project consortium to collaborate on a common platform to support a community development project named BTP2. The core aim of the project consortium is to support the European SME sector within the domain of `Business Transfer Process` following the targeted period of two years $(01.11 .2010-31.10 .2012)$. After the successful exposure and implementation of the Business Transfer Programme, through the pilot process in 'Austria' and 'Italy', the second phase of the project took its practical piloting exposure and implementation in `Finland`, 'Poland’, and `Portugal'.

\section{METHODOLOGY}

The name of the project was named as the `Business Transfer Programme 2 (BTP2) and it was the advanced phase of the 'Business Transfer Programme` BTP pilot project. Main highlights of the initial Business 
transfer programme (BTP) were; to support the learning process for the prospective entrepreneurs, business successors, mentors or any relevant stakeholders, interested in upgrading their knowledge base specifically related to the business transfer process, through a tailor made training programme in combination with a web based screening tool. The screening tool was especially designed and tested to support the business successors or the buyers and transferors who are interested or intending to go through the business transfer process. The main aim of the said model, through its evaluation process and feedback, is to further provide adaptation basis to support and refine the BTP2 curriculum and Screening tool to cater the ever changing needs and demands as well as for the greater global out reach. As mentioned in the earlier part of the literature that BTP 2 is a project co-funded by the European Commission under the Leonardo da Vinci programme.

\section{Description of the project planning till the pilot programme implementation}

The under discussion project i.e, Business Transfer Programme 2, termed as BTP 2 was the continuation of the former Leonardo da Vinci project named as Business Transfer Programme (BTP). The main achievements of the BTP project were the formation of a practically orientated curriculum, ably supported by an online screening tool for business successors and transferors. The core purpose behind the above mentioned arrangements were to establish a development system for the new entrepreneurs, who are either entering into the business world through any sources; i.e., either the process of succession, a new business start-up initiative or after taking over the business through the sale and purchase arrangement. Keeping in view of the above, a curriculum was designed as a result of an extensive amount of brainstorming among the highly able and well experienced researchers, who were responsible for establishing the consortium by the process of resource collaboration representing seven European countries namely, Austria, Italy, Portugal, Poland, Netherlands, Sweden and Finland. The designed BTP programme was then successfully piloted in Austria and Italy. The curriculum and screening tool was then enhanced on the basis of the feedback received from the piloting countries for its implementation in Finland, Portugal and Poland under the title of BTP2. Accordingly, the BTP process continued in the form of BTP 2 programme having seven course modules including finance, law, business analysis, communication and negotiation, strategic human resource management, soft skills and marketing, dully supported by the screening tool, on the piloting group of countries i.e., Finland, Portugal and Poland, as a test run so that the results of the trainings can be utilized as a benchmark to assure a standardized training on a European level.

\section{The outcomes of the project were to provide two dimensional assurances}

The primary assurance was to increase the knowledge base of the business successors or buyers and to enhance their ability as well as the competency level for the business take-over or the transfer process. The BTP 2 provided information on important business areas and offered support in handling the difficulties involved in the transfer process. The screening tool included in the programme as a technical instrument to enable the initial business feasibility and viability analysis. The secondary aim of the project implementation was to take part in the process of SME sector's development in Europe with a special focus on the Business transfer process. This aim was additionally in line with the European Commission's Europe 2020 Strategy and the Small Business Act 2008. 


\section{RESULTS AND DISCUSSIONS}

The combined results of BTP2 's pilot trainings, which were gathered from the piloting countries i.e., Poland, Portugal and Finland are described below:

\section{Table 2. Time table of the BTP2 training sessions conducted in Finland, Portugal and Poland.}

\begin{tabular}{|c|c|c|c|c|}
\hline Countries & From & To & $\begin{array}{l}\text { Number of } \\
\text { Participants }\end{array}$ & Total face to face training Sessions \\
\hline Finland & 08.05 .2012 & 29.09.2012 & 11 & $\begin{array}{l}\text { Nine face to face Sessions (i.e., nine modules } \\
\text { sessions, one opening and one closing session. In } \\
\text { addition to one introductory session. }\end{array}$ \\
\hline Portugal & 12.12 .2011 & 16.03 .2012 & 10 & $\begin{array}{l}\text { Nine face to face sessions,(i.e., seven module } \\
\text { sessions, one opening and one closing. }\end{array}$ \\
\hline Poland & 12.02 .2011 & 13.04.2012 & 11 & $\begin{array}{l}\text { Nine face to face sessions, (i.e., seven modules, } \\
\text { one opening and one closing session). }\end{array}$ \\
\hline
\end{tabular}

The table 2 above Reflects the time schedule of the trainings conducted in the three pilot partner countries i.e. Finland, Portugal and Poland along with the participation level). The referred trainings were evaluated at four levels. First level focused on tracking the course participant's attendance, on the agreed and approved training dates by the three pilot project partners' countries i.e., Finland Portugal and Poland. The details are as follows:

The course wise attendance behavior of the course participants during all the three pilot partner countries is as follows:

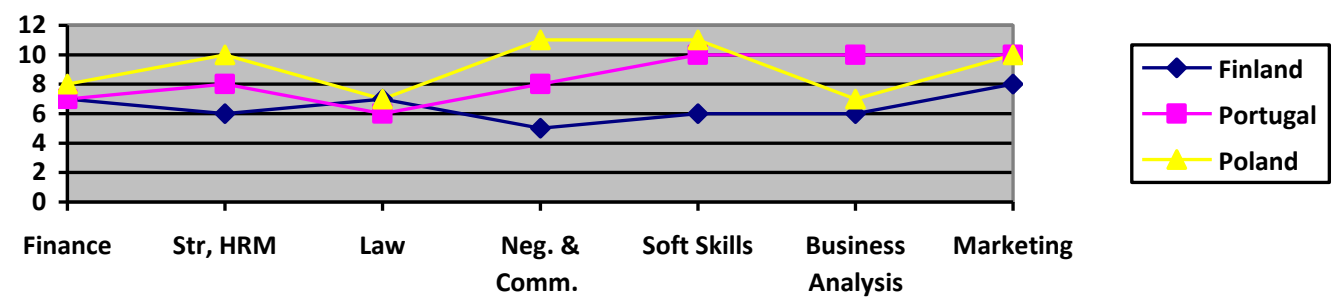

(Fig 1.

A reflection of the comparative course wise participation behaviour)

The attendance behaviour of the participants reflected that finance, law and marketing got much attention in Finland, strategic human resource management, negotiation and communication, soft skills, business analysis and marketing were the most popular choice among the trainees in Portugal, while strategic human resource management, negotiation and communication, soft skills and marketing were in Poland. The quality assessment of the BTP 2 training within the three pilot training countries is graded as follow:

Table 3: Comparative quality assessment of the BTP training sessions conducted in the three piloting countries (Finland, Portugal and Poland).

\begin{tabular}{l|lll} 
Countries & Very Good & Good & Not so Good
\end{tabular}




\begin{tabular}{|l|llll}
\hline Finland & $50 \%$ & $50 \%$ & $0 \%$ & $0 \%$ \\
\hline Portugal & $05 \%$ & $95 \%$ & $0 \%$ & $0 \%$ \\
\hline Poland & $10 \%$ & $90 \%$ & $0 \%$ & $0 \%$ \\
\hline
\end{tabular}

The table-3 above reflects the comparative analysis on the BTP training session's quality. The above table reveals that $50 \%$ of the course participant in Finland rated the training quality as 'Very Good' and 50\% as 'Good'. In addition, only $5 \%$ and $10 \%$ of the course participants considered the quality as 'Very Good' while 95\% and $90 \%$ rated the course quality as 'Good from Portugal and Poland respectively. However, among all the three piloting countries, no participant assessed the training quality as 'Not so good` or 'Poor'. These results have reflected overwhelming support towards the BTP2 initiative. To check the usefulness of the seven modules course package, the feedback from the course participants were obtained after the end of each module through the specialized questionnaires. These questionnaires were designed in the way to highlight all the dimensions of the each specific course module. Henceforth, the feedback received from the course participants representing the three piloting countries (i.e., Finland, Poland and Portugal) revealed the following response pattern:

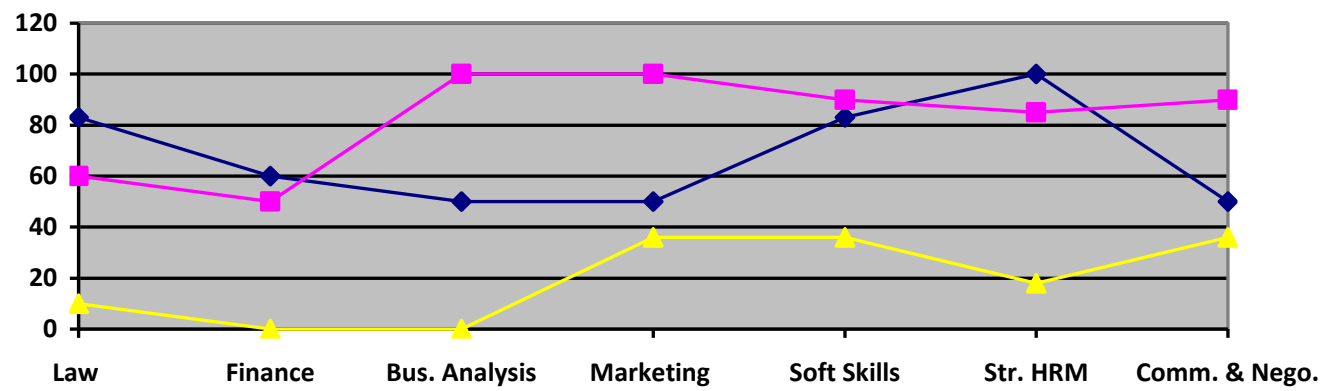

(Fig2. Reflection of a comparative scenario on usefulness attached with each course module, among three piloting countries i.e., Finland, Portugal, Poland.)

The above graphic representation (Fig.2) reflected the trend of the participants from the three pilot training countries in terms of rating the usefulness of the seven course choices available in the form of the BTP 2 . Strategic human resource management, law and soft skills were considered as the most useful course choices by the course participants from Finland, business analysis, marketing, soft skills, strategic human resource management and communication and negotiation were the considered as the most useful by the course participants in the Portugal pilot trainings while marketing, soft skills and communication and negotiation were regarded as the most useful by the course participants from Poland pilot trainings. The above trend reflected that the course module for 'soft skills' was unanimously considered useful in all the three pilot training countries by their respected participants.

Overall effectiveness of the training among the three piloting countries were investigated through the feedback received from the trainers. Specialized feedback tool was designed covering the relevant dimensions i.e., objectiveness of the training, learning material, organization, screening tool, as well as the information about the online learning platform etc.). The combined results reflecting the trends from the piloting countries are as follows: 


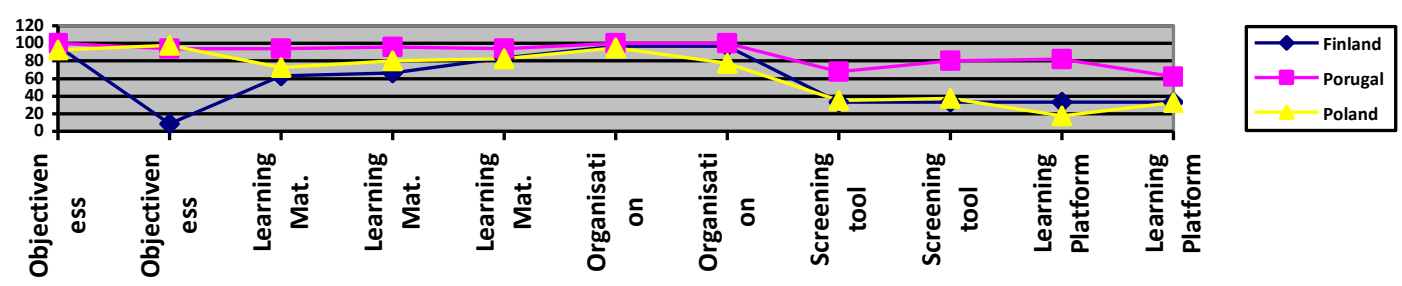

(Fig.3 Reflection of performance gaps associated with the overall effectiveness of the trainers (i.e., representing the three piloting countries Finland, Portugal and Poland.)

The above figure gives an overview of the performance assessment of the BTP2 training programme. For the above, the basis of the evaluation was the feedback gathered from the trainers involved in the BTP2 programme in the piloting countries. Figure .3 clearly shows objectiveness, learning material and organization of the BTP2 training programme as the key elements in all the three piloting venues while screening tools and learning platform offered in the BTP2 training programme were considered as the weak areas in the package all the participants except the ones in Portugal. This can be attributed to the fact that in Finland the organizers faced with limited time duration to implement the BTP2 pilot training programme. Consequently, the course facilities like screening tool and online learning platform could not be utilized effectively in Finland. In Poland, it was seen that more than one year's duration was utilized to run the BTP2 pilot training. Henceforth, the longer time gaps affected the seriousness and the level of concentration by the training participants as well as the trainers. However, in Portugal almost all the modules and support tools of BTP2 were effectively utilized.

\section{Success factor of the BTP2 pilot implementation}

The aims behind the implementation of the BTP 2 training programme in three pilot countries was to broaden the knowledge base and skill level of the prospective business buyers and successors on the basis of the pilot training results. The innovative facilities attached with the BTP 2 i.e., the learning platform and the screening tool holds added strength to support the business successors and buyers to cope with the issues related to the business transfer process.

The ultimate aim of the BTP 2 project was to support the overall development of the SME Sector within the European region to defeat the effects of local rescission which has affected the local business scene since 2009.

\section{A `Missing link` in the chain of Business Transfer Process loop}

Though the BTP 2 Pilot training programme got much appreciation and acknowledgement by the users for the selection of the course modules and the facilities like screening tool and online learning platform but it got some criticism for lacking the following aspects:

- The course material to be refined in terms of adding knowledge base related to the local target users.

- The courses material should include the case studies highlighting the information related to the specific locality and local user's needs, 
- The BTP 2 training programme should include information and knowledge base targeting the ‘Business Transfer Process` instead of providing the general concepts of business subjects,

- Another key area which is currently missing is the factor of 'emotions` usually dominant from the 'business Seller's 'point of view. Since currently, the business transfer process is focused from the buyer's point of view.

\section{DISCUSSION AND CONCLUSION}

In accordance with the facts reported in the European commission's recent report on the performance of SME's in European region, released on 15th October 2012, Finland and Poland are among the European states having 'PN' category. i.e., the countries in the category of 'positive real value growth but having a negative employment growth while Portugal has the 'NN' categorization i.e. having negative real value added and employment growth. The same attitude can be seen with the results of the pilot training feedback scores as well as the behavior pattern of the BTP2 training programme. The course participants as well as the trainers of the Portugal pilot partner state showed utmost interest in the overall BTP2 training process thinking it to be a solution to solve their personal as well the national level weak business scenario. They even tried to focus on the 'Learning platform` and the `screening tool to obtain as much knowledge as possible. The scores on the different dimension of the overall training programme by the trainees as well as the trainers are more higher as compared to the ones given by the 'Finnish` or the 'Poland pilot training partner states. Finland is considered as one of the European state having heavy concentration of the SME sector into the knowledge intensive engineering cum industrial sector. Therefore, the SME sector of Finland is quite reformed and well established already, having the supports of public sector as well as the private sector in the field of resource development based options; i.e., web based tools as well as the corporate training actors busy in the process of SME development.

Henceforth, the BTP2 training programme got some criticism for focusing on too general level knowledge base for the area. The behavior pattern gathered from the Poland pilot partner's effort on BTP2 Training Programme reflected the similar attitude then that of the Finnish pilot partner's but with little bit less intensity. The difference was that in Finland more mentors took part in the programme since in the country, the trainers, in general, are more involved in such activities, while in Poland the prospective business buyers and the successors were more interested in the programme, since their systems with regards to the SME sector development programs are not as well established as compared to the ones in Finland. However, the BTP 2 training programme received considerable amount of interest from the trainees as well as the trainers. The opportunity provided much insight about how to further refine the BTP 2 so that it can be implemented in the other parts of Europe for the SME sector uplift to combat the ills of the regional recession which is affecting the overall economic sector since 2009.

\section{Future Research Avenues}

The BTP2 training gave enough insight to offer basis for future research opportunities. Our research effort can open following avenues for further research and testing:

A. The comparative role of 'business incubators` if attached with the BTP2 training programme,

B. The role of business sellers`emotions in the business transfer process. 


\section{REFERENCES}

Andrew Motte's English translation: Newton, Isaac (1846), Newton's Principia: the mathematical principles of natural philosophy, New York: Daniel Adee, pp. 72, (Retrieved from:

http://www.archive.org/details/newtonspmathema00newtrich).

Allinson, G., Braidford, P., Houston, M., Robson. P. and Stone, I. (2007), Promoting Success in the Small Business Transfer Market, Centre for Entrepreneurship, Durham Business School.

Ahmad, N and R. G. Seymour (2008). "Defining Entrepreneurial Activity: Definitions Supporting Frameworks for Data Collection”. From OECD Statistics Working Papers, 2008/01, OECD Publishing. http://dx.doi.org/10.1787/243164686763.

Bachkaniwala, D., Wright, M. and Ram, M. (2001). Succession in South Asian FamilyBusinesses in the UK. International Small Business Journal 19(4): 15-27.

Berent, M., Uhlaner, L., Gibcus, P., Timmermans, N. and Van Teeffelen, L. (2009), Planning and successor characteristics as determinants of successful ownership transfer in SME's: an empirical study, Paper presented at BABSON Conference, June 2009, Babson Park, MA, USA.

Becker, G.S. (1975). Human capital: A theoretical and empirical analysis, with special reference to education. (2nd ed.). National Bureau of Economic Research. New York, NY: Columbia University Press. Bomberg. E, Peterson. J, and Richard C. 2012. The European Union: How Does it Work? (3rd ed.): Oxford University Press.

Cantillon, R. 1755/1931. Essai sur la Nature du Commerce en Général. London, UK: MacMillan. Website. "European". Oxford English Dictionary. From: http://www.oed.com/view/Entry/65099? redirectedFrom=European\#eid. Retrieved 3 October 2011.(Ref. European Commission (2003-05-06). "Recommendation 2003/361/EC: SME Definition". http://ec.europa.eu/enterprise/enterprise_policy/sme_definition/index_en.htm).

Cardon, M., C. Zietsma, P. Saparito, B. Matherne and Davis. C. 2005. "A tale of passion: New insights into entrepreneurship from a parenthood metaphor." Journal of Business Venturing, 20:23-45

Sharma, P., Chrisman, J. J., Pablo A. L., \& Chua, J. H. (2001). Determinants of initial satisfaction with the succession process in family firms: A conceptual model. Entrepreneurship Theory and Practice, 25(3),17-35. Small Business Service; Passing the baton - encouraging successful business transfers, URN 04/1888, available from www.sbs.gov.uk: (Retrieved on 2012.11.23) http://www.bis.gov.uk/files/file38277.pdf.

Schumpeter, J A. (1934). The Theory of Economic Development: An Inquiry into Profits, Capital, Credit, Interest, and the Business Cycle. Cambridge, MA: Harvard University Press.

Hadjimanolis, A. and Dickson, K. (2000): Innovation strategies of SMEs in Cyprus, a small developing country. International Small Business Journal, 18 (4): 62-79.

Hafer, Rik W. (2011) “Entrepreneurship \& State Economic Growth” Unpublished research paper, Southern Illinois University, Edwardsville, IL 


\section{Journal of Global Strategic Management | V. 8 | N. 1 | 2014-June | isma.info | 38-48 | DOI: 10.20460/JGSM.2014815651}

Husain, J. (2009), “Lessons Learnt from Business Mentoring Practices”, Business Review, Cambridge, Vol. 14, Number 1, pp. 300-305.

Husain, J. (2013) Training programs for business owners - A Strategic framework. Journal of Global Strategic Management. 14(2): 16-23.

Kets de Vries, M. F. R.(1993).The Dynamics of Family Controlled Firms: The Good News and the Bad News. Organizational Dynamics 21(3): 59-71.

Lazear, E.P. (2005), Entrepreneurship. Journal of Labor Economics, 23(4):649-680

Le Breton-Miller, I., Miller, D. and Steier, L. (2004), Toward an integrative model of effective FOB succession, Entrepreneurship Theory and Practice, 28 (4), 305-309.

Meijaard, J. (2005), Business Transfers in the Netherlands, In: Snijders, J. and Haane, Y. (Eds), Entrepreneurship in the Netherlands, Business Transfer: a new start, EIM, Zoetermeer.

Venter, E., Boshoff, C., \& Maas, G. (2005). The influence of successor-related factors on the succession process in small and medium-sized family businesses. Family Business Review, 18, 283-303.

Van, Teeffelen, L. (2010), Exploring success and failure in small business ownership transfers, Nyenrode Business Universiteit, Breukelen, the Netherlands.

Van, Teeffelen, L.(2012), Avenues to improve success in SME Business Transfers: reflections on theories, research and policies, 5 BIEM -Symposium,Europa-Universität Viadrina Frankfurt, Germany. 